\title{
Highly Chemical Reactive Ion Etching of Gallium Nitride
}

\author{
F. Karouta ${ }^{1}$, B. Jacobs ${ }^{1}$, I. Moerman ${ }^{2}$, K. Jacobs ${ }^{2}$, J.L. Weyher ${ }^{3}$, S. Porowski ${ }^{3}$, \\ R. Crane ${ }^{4}$ and P.R. Hageman ${ }^{4}$ \\ ${ }^{1}$ COBRA Inter-University Research Institute on Communication Technology \\ Eindhoven University of Technology - Department of Electrical Engineering \\ P.O.Box 513, NL-5600 MB Eindhoven, Netherlands \\ ${ }^{2}$ Department of Information Technology (INTEC), University of Ghent, \\ Sint Pieternieuwstraat 41, 9000 Ghent, Belgium \\ ${ }^{3}$ High Pressure Research Center, Polish Academy of Sciences, \\ Sokolowska 29/37, 01-142 Warsaw - Poland \\ ${ }^{4}$ Experimental Solid State Physics III, RIM, University of Nijmegen,
} Toernooiveld 1, 6525 ED Nijmegen, Netherlands

\begin{abstract}
A highly chemical reactive ion etching process has been developed for MOVPE-grown GaN on sapphire. The key element for the enhancement of the chemical property during etching is the use of a fluorine containing gas in a chlorine based chemistry. In the perspective of using GaN substrates for homo-epitaxy of high quality GaN/AlGaN structures we have used the above described RIE process to smoothen Gapolar GaN substrates. The RMS value, measured by AFM, went from $20 \AA$ (after mechanical polishing) down to $4 \AA$ after 6 minutes of RIE. Etching N-polar GaN resulted in a higher etch rate than Ga-polar materials (165 vs. $110 \mathrm{~nm} / \mathrm{min}$ ) but the resulting surface was quite rough and suffers from instability problems. Heat treatment and $\mathrm{HCl}$ dip showed a partial recovery of Schottky characteristics after RIE.
\end{abstract}

\section{Introduction}

GaN materials are very interesting for optoelectronic and microelectronic applications like blue and green LEDs, blue lasers, UV photodetectors, high power and high temperature HEMTs. GaN and its related materials (AlGaN, InGaN, InAlGaN) are most commonly grown, using metal organic vapour phase epitaxy (MOVPE) or molecular beam epitaxy (MBE), on $\alpha-\mathrm{Al}_{2} \mathrm{O}_{3}$ substrates. For specific applications like high power transistors, silicon carbide substrates are used because of their higher thermal conductivity. The lattice mismatch remains high in both cases with an advantage for $\mathrm{SiC}$, and hence epitaxial layers suffer from stress induced by the lattice mismatch which results in a very high dislocation density (in the range of $10^{8}-10^{10} \mathrm{~cm}^{-2}$ ). GaN bulk materials form an attractive solution to circumvent the problems of lattice mismatch encountered in hetero-epitaxy by allowing a perfect lattice-matched epitaxy.

Dry etching of GaN has been extensively investigated using numerous plasma-based machines and sources. High etch rate $(1.3 \mu \mathrm{m} / \mathrm{min})$ was reported using an electron cyclotron resonance (ECR) [1]. Conventional reactive ion etching (RIE) generally shows lower etch rates and leads to higher level of induced damages. We have developed a highly 
chemical reactive ion etching process using a conventional parallel plate reactor. In a previous work [2] we reported a fourfold increase in etching rate when simply adding $\mathrm{SF}_{6}$ to $\mathrm{SiCl}_{4}+\mathrm{Ar}$. This highly chemical RIE process is based on the choice of the gases used for etching. At a power of 300 Watts we achieved an etch rate of $430 \mathrm{~nm} / \mathrm{min}$ which is twice the etch rate reported by Feng et al [3] of $210 \mathrm{~nm} / \mathrm{min}$ at the same power using $\mathrm{BCl}_{3}$ $+\mathrm{SF}_{6}$.

In this paper and after a short description of our RIE process, we shall present the results of our RIE investigation on bulk GaN single crystals. We have compared etch rates and morphology after RIE on Ga- and N-polar surfaces. We also have studied the influence of this RIE process on Schottky diodes made on $n-G a N$.

\section{Experimental}

The plasma machine is a load-locked conventional RF-powered reactor (Oxford Plasmalab 100) with an oil-free pumping system (dry pump + magnetically levitated turbo pump). Silicon nitirde as well photoresist were used for masking. All etch experiments were performed at room temperature. Non-intentionally doped MOVPE-grown GaN on $\alpha$ $\mathrm{Al}_{2} \mathrm{O}_{3}$ (0001) substrates was used to investigate the RIE process as a function of gas flow, RF-power and pressure. The optimized process was used for the study on Ga- and Npolar GaN bulk materials. The etch depth was measured using a Tencor-200 surface profiler while the morphology was characterized qualitatively by scanning electron microscopy (SEM) for the MOVPE-grown $\mathrm{GaN}$ and quantitatively by atomic force microscopy (AFM) in the case of bulk GaN.

\section{Etching of MOVPE-grown GaN}

Adding $\mathrm{SF}_{6}$ to the more conventional $\mathrm{SiCl}_{4}$ :Ar chemistry has led to a fourfold increase of etch rate. A relatively low power process at 105 Watts using $\mathrm{SiCl}_{4}: \mathrm{Ar}_{\mathrm{SF}}(10: 10: 2$ $\mathrm{sccm})$ at 40 or $20 \mathrm{mTorr}$ resulted in an etch rate of $\sim 100 \mathrm{~nm} / \mathrm{min}$ instead of $22 \mathrm{~nm} / \mathrm{min}$ at the same conditions without $\mathrm{SF}_{6}$. The DC bias was $\sim-300$ V. Figure 1 shows a typical etched and very smooth $\mathrm{GaN}$ surface obtained after 6 minutes of RIE etching.

Figure 2 clearly shows the influence of $\mathrm{SF}_{6}$ in the RIE process. We believe that etch products, when using $\mathrm{SF}_{6}$, are $\mathrm{GaCl}_{3}$ and $\mathrm{NF}_{3}$. The fact that $\mathrm{NF}_{3}$ is more volatile (boiling point of

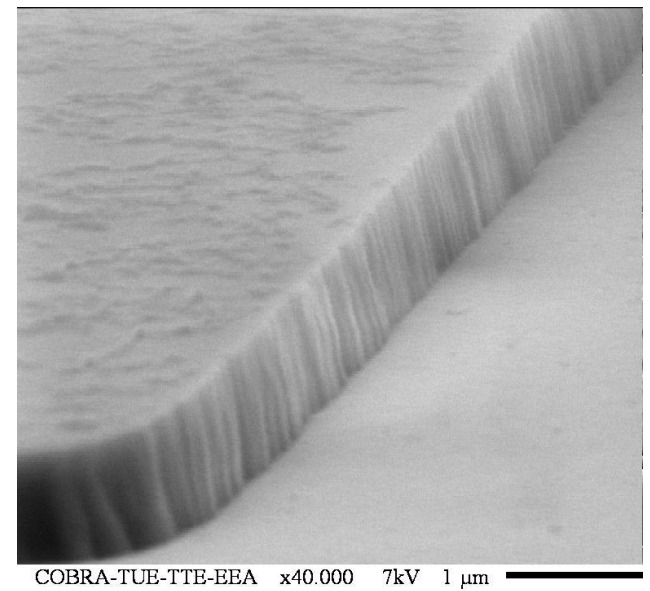

Figure 1- A SEM photograph of a very smooth surface after RIE using the optimized process at 40 mTorr. 
$-129^{\circ} \mathrm{C}$ ) than $\mathrm{NCl}_{3}$ (boiling point around $71^{\circ} \mathrm{C}$ ) explains the fourfold increase of etch rate. Since the etch rate with only argon at $105 \mathrm{~W}$ and $40 \mathrm{mTorr}$ was $9 \mathrm{~nm} / \mathrm{min}$, this demonstrates the highly chemical property of our RIE process. The decrease in etch rate at higher $\mathrm{SF}_{6}$ flow is presumably due to the fact that more electrons are subject to collisions which do not result in active species. Furthermore, we have achieved a maximum etch rate of $430 \mathrm{~nm} / \mathrm{min}$ using the same chemistry at $300 \mathrm{~W}$ (DC bias around $-600 \mathrm{~V})$. This is a world record when considering etching results in conventional RIE reactors. Feng et al, have used a comparable chemistry based on $\mathrm{BCl}_{3}: \mathrm{SF}_{6}$ and they reported a maximum etch rate of $210 \mathrm{~nm} / \mathrm{min}$ instead of $50 \mathrm{~nm} / \mathrm{min}$ without $\mathrm{SF}_{6}$. This fourfold increase of etching rate is remarkably similar to the one we obtained when adding the same fluorinated gas. Adesida et al. [4] have not noticed any change in etch rate $(50 \mathrm{~nm} / \mathrm{min})$ when adding $\mathrm{SiF}_{4}$ to a $\mathrm{SiCl}_{4}$-based chemistry. These results can be explained by the dissociation energies of the various gases. For instance, these energies are 93.6 and $145.4 \mathrm{kcal} / \mathrm{mole}$ for $\mathrm{SF}_{6}$ and $\mathrm{SiF}_{4}$ respectively, while for $\mathrm{SiCl}_{4}$ and $\mathrm{BCl}_{3}$ these values are 94.1 and $110 \mathrm{kcal} / \mathrm{mole}$ respectively. It is clear that the $\mathrm{SiCl}_{4}+\mathrm{SF}_{6}$ combination has the lowest dissociation energies and hence forms the best choice among these gases.

\section{Etching of bulk GaN crystals}

Chemically assisted ion beam etching (CAIBE) using $\mathrm{Cl}_{2} / \mathrm{Ar}$ (which is dominated by physical sputtering) and $\mathrm{RIE}$ using $\mathrm{Cl}_{2}: \mathrm{Ar}: \mathrm{CH}_{4}$ of bulk $\mathrm{GaN}$ were already reported in literature $[5,6]$. We have used the following RIE process $\left\{\mathrm{SiCl}_{4}: \mathrm{Ar}_{\mathrm{SF}}(10: 10: 2 \mathrm{sccm})\right.$ at 105 Watts and 40 mTorr to remove polishing damages from bulk GaN single crystals. It is worth noticing that "standard" MOVPE grown hetero-epitaxial GaN is Ga-polar while GaN single crystal substrates present the advantage of having the two polarities and by simply putting the sample upside down the polarity of homo-epitaxial layer can be changed. The GaN single crystals were grown from liquid gallium saturated with molecular nitrogen at $1600^{\circ} \mathrm{C}$ and at nitrogen pressure of about $15 \mathrm{kbar}$ [7].

Because of the small size of the GaN crystals, sapphire blocks of $2 \mathrm{x} 1 \mathrm{~mm}^{2}$ were used for masking in order to measure the etch rates. Two samples of different polarity were simultaneously etched for 6 minutes in each run to realize a realistic comparison and to exclude any reproducibility problems. In addition to the etch rate measurements and SEM photography the morphology of the surface was measured by AFM to determine the RMS roughness (peak-valley differences) in substrates with both polarity. 
After the mechanical polishing of Ga-polar substrates with diamond paste $(0.1 \mu \mathrm{m}$ final grade $)$, the surface roughness had an RMS value of 20-30 $\AA$. A cleaning in boiling acetone and iso-propanol was carried out before the RIE experiments. Notice that scratches caused by the polishing are clearly visible (fig. 3).

After the RIE process an etch rate of $100-110 \mathrm{~m} / \mathrm{min}$ was measured on these Ga-polar single GaN crystals which is quite similar to that obtained earlier for MOVPE grown hetero-epitaxial GaN.

This is quite remarkable since the

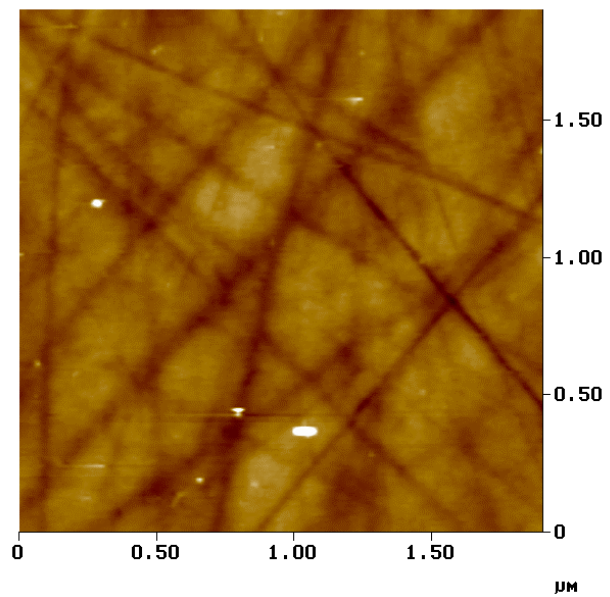

Figure 3- An AFM photograph of Ga-polar surface after mechanical polishing.

bulk GaN substrates have much less growth-related defects. This result converge with our previous statement over the highly chemical component of the used RIE process as the etch rate does not depend on density of defects. In conclusion the surface becomes much smoother where RMS value of $4 \AA$ was measured. Thus a clear polishing effect of the Gapolar surface by RIE is demonstrated. A drawback of this result was the fact that a random distribution of "pillars" has been found (fig. 4-left). After examination of several samples at different RIE conditions we have found that residual organic contaminating particles are the reason of the nucleation of pillars. Performing a 6-minute $\mathrm{O}_{2}$ plasma in the same reactor prior to the RIE process of $\mathrm{GaN}$ was effective to get rid of any remnant contamination of the surface and subsequently of the "pillars". Figure 4-right shows a featureless Ga-polar surface obtained after combined $\mathrm{O}_{2}$ plasma cleaning and RIE. The resulted surface allowed the MOVPE-growth of high quality homo-epitaxial layers [8].
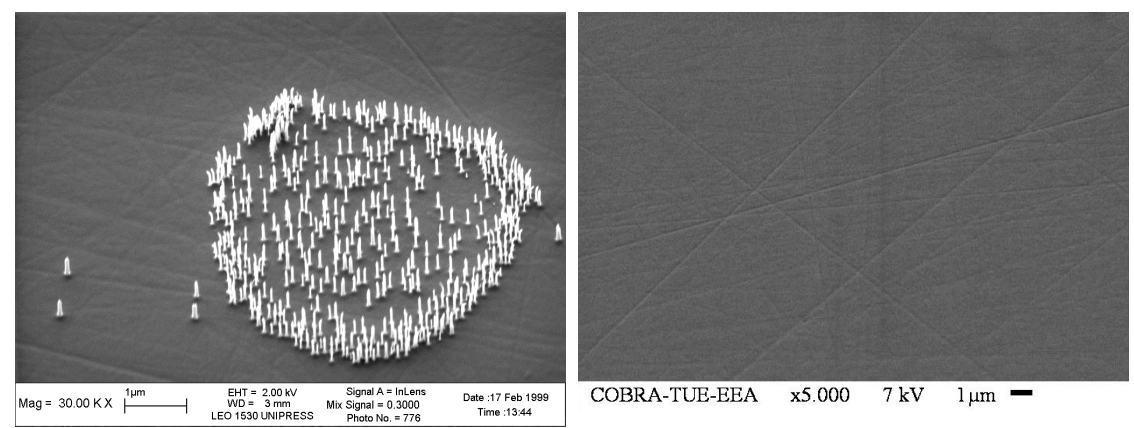

Figure 4- A clustering of residual pillars are shown (left) while using an oxygen plasma prior to RIE resulted in a smooth and pillar-free surface (right). 
The N-polar (0001) GaN crystals were subjected to the same mechanical polishing as for Ga-polar substrates followed by a careful mechano-chemical polishing in $\mathrm{KOH}$-based solutions. This led to a very smooth surface with, routinely obtained, atomic height differences (RMS of 1-2 $\AA$ ). Using such crystals as damage-free epi-ready substrates led to a very good homo-epitaxial growth of $\mathrm{GaN}$ [9]. These very smooth samples were also subject to the same RIE process as performed on Ga-polar crystals. An etch rate of $165 \mathrm{~nm} / \mathrm{min}$ was now measured but

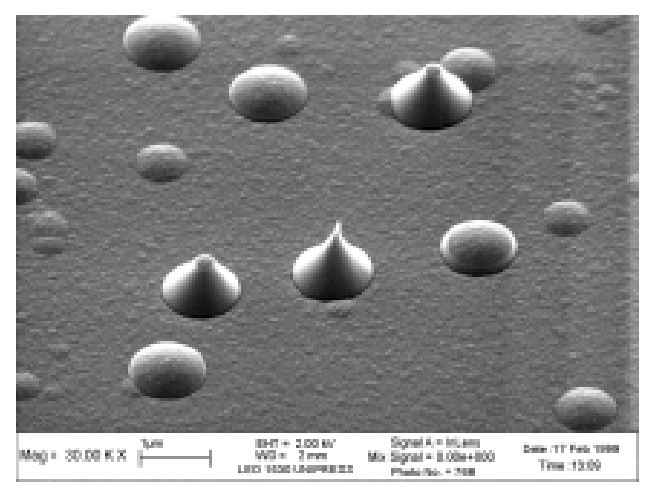

Figure 5- A rough N-polar surface after RIE with hillocks and mounds. a clear deterioration of the surface morphology was observed. The RMS value increased from $2 \AA$ to $20 \AA$ as shown in figure 5 .

Besides this overall roughening, large cone-shaped hillocks randomly distributed were present which are probably caused by inversion domain areas. These localized Ga-polar areas are etched slower than the adjacent N-polar surface and hence lead to the formation of the hillocks. Moreover, the increased roughness after RIE can be related to the poor stability of the N-polar surface already observed during high temperature MOVPE [10].

\section{Electrical behaviour}

We have investigated the influence of the RIE process on the electrical properties of GaN layers. Schottky diodes were fabricated on n-type $\mathrm{GaN}$ epitaxial layer $\left(2 \times 10^{17} \mathrm{~cm}^{-2}\right)$. The ohmic contacts were made using $\mathrm{Ti} / \mathrm{Al}(35 / 115 \mathrm{~nm})$ annealed at $600^{\circ} \mathrm{C}$ for 30 seconds resulting in a contact resistance of $0.1 \Omega . \mathrm{mm}$. A platinum layer of $100 \mathrm{~nm}$ thickness was used for the Schottky contacts. I-V measurements were performed to extract the reverse curent and the ideality factor of the diode. These values were investigated with various pre-treatments of the surface prior to the Schottky metallization. The best partial recovery was achieved when the material was subjected to a short RIE process followed by a $\mathrm{HCl}$ dip and a heat treatment at $600^{\circ} \mathrm{C}$ during 30 seconds. The reverse current and the ideality factor were found to be respectively $4 \times 10^{-4} \mathrm{~A} / \mathrm{mm}(-20 \mathrm{~V}), 1.12$ (as-grown) and $1 \times 10^{-3}$ $\mathrm{A} / \mathrm{mm}, 1.12$ (after RIE, $\mathrm{HCl}$ dip and heat treatment).

Further investigation of the RIE process in conjunction with/or $\mathrm{O}_{2}$-plasma, $\mathrm{HCl}$ dip and heat treatment and their influence on the electrical characteristics of $\mathrm{GaN}$ and $\mathrm{AlGaN}$ layers are undergoing. 


\section{Conclusions}

A highly chemical reactive ion etching process has been demonstrated based on a combined fluorine and chlorine chemistry. Adding $\mathrm{SF}_{6}$ to $\mathrm{SiCl}_{4}+\mathrm{Ar}$ resulted in a fourfold increase of etch rate. This RIE process is suitable for removing work damages from Gapolar substrates and realizing a final polishing of Ga-polar $\mathrm{GaN}$ single crystals making them epi-ready.

\section{Acknowledgements}

B. Jacobs would like to thank the Netherlands Organisation for Applied Scientific Research (TNO-FEL) for support and J.L.Weyher wishes to thank NATO Scientific Affair Division for the grant HTECH:LG 972924.

\section{References}

[1] C.B. Vartuli, S.J. Pearton, J.W. Lee, J. Hong, J.D. Mackenzie, C.R. Abernathy and S.J. Shul, Appl. Phys. Lett. 69, 1426 (1996).

[2] F. Karouta, B. Jacobs, P. Vreugdewater, N.G.H. v. Melick, O. Schön, H. Protzmann, M. Heuken. Electrochemical and Solid State Letters, 2, (5), 240241, (1999).

[3] M.S. Feng, J.D. Guo, Y.M. Lu, E.Y. Chang, Materials Chemistry and Physics, 45, 80 (1996).

[4] I. Adesida, A. Mahajan and E. Andideh, Appl. Phys. Lett. 63, 2777 (1993).

[5] M. Schauler, F. Eberhard, C. Kirchner, V. Schwelger, A. Pelzmann, M. Kamp, K.J. Ebeling, F. Bertram, T. Riemann, J. Christen, P. Prystawko, M. Leszczynski, I. Grzegory, S. Porowski, Appl. Phys. Lett., 74, (8), 1123-1125, (1999).

[6] P. Prystawko, M. Leszczynski, B. Beamount, P. Gibart, E. Frayssinet, W. Knap, Phys. Stat. Sol. B, 210, (2), 437-443, (1998).

[7] S. Porowski, J. Crystal Growth 166, 583-589, (1996).

[8] J.L. Weyher, A.R.A. Zauner, P.D. Brown, F. Karouta, A. Wysmolek, P.R. Hageman, S. Porowski, accepted for presentation at the $3^{\text {rd }}$ International Conference on Nitride Semiconductors, July 5-9, Montpellier, France, (1999). Accepted for the proceedings in journal of Physica Status Solidi.

[9] J.L Weyher, S. Müller, I. Grzegory, S. Porowski, J. Crystal Growth, 182, 17-22, 1997.

[10] J.L. Weyher, P.D. Brown, A.R.A. Zauner, S. Müller, C.B. Boothroyd, D.T. Foord, P.R. Hageman, C.J. Humphreys, P.K. Larsen, I. Grzegory, S. Porowski, J. Crystal Growth, 204, 419-428, 1999. 